\title{
Surgical Pearl: Small Suction Syringe for Producing Blister
}

\author{
Muhammed Mukhtar (iD) ${ }^{1, *}$ \\ ${ }^{1}$ Mukhtar Skin Centre, Katihar, India \\ "Corresponding author: Mukhtar Skin Centre, Katihar Medical College Road, Katihar, India. Email: drmmukhtar20@gmail.com
}

Received 2020 June 20; Accepted 2020 August 13.

Keywords: Suction Syringe, Small, Stable, Blister, Suction Height/Column, Radius, Volume, Cylinder, Hemisphere, Volume Ratio

\section{Dear Editor,}

The 3-way cannula- syringe and modified syringe are larger devices used for producing blisters $(1,2)$. However, 3-way cannula-cup is a small, stable device compared to larger suction devices (3). To use this advantage of a small suction cup, the suction syringe is modified into a small device.

To achieve a small, stable, and effective suction syringe, I took a disposable syringe, and its barrel and piston were removed by a heated surgical blade while keeping the suction height at its radius value $(h=r)$ to get a blister of height radius (r). At height ( $\mathrm{r}$ ), the volume of the cylindrical suction column is 1.5 times the volume of the produced hemispherical blister, as per calculation. [Suction volume of syringe (cylinder) at the height of the syringe radius $(r)=$ $\pi \mathrm{r}^{2} \mathrm{xh}=\pi \mathrm{r}^{3}$ and volume of the blister (hemisphere) $=1 / 2 \times$ $4 / 3 \pi r^{3}=2 / 3 \pi r^{3}$; therefore, the ratio of the suction volume of suction column (of the syringe) to the volume of blister can be calculated as $\left.\pi r^{3} \div 2 / 3 \pi r^{3}=3 / 2=1.5\right]$. After this, a little but larger, the opening is designed in the piston to tie a loop of thread as well as to insert a $16 \mathrm{G}$ needle. Vaseline was applied over the aseptic skin suction site, the rim of the syringe, and piston top in order to achieve better air sealing. After placing the syringe over the site, the piston was pulled up by a metal hook in order to insert it into the thread loop, not into the opening. Then, a $16 \mathrm{G}$ needle was put into the opening of the piston to sustain the suction process (Figure 1A-G). Vesicles were produced after 15 to 20 minutes and started to coalesce in 30 to 40 minutes, and the blister was formed in 50 to 60 minutes (Figure $2 \mathrm{~A}-\mathrm{H}$ ). Hence, it can be argued that the suction syringe was effective even at the suction column of its radius height.

\section{Footnotes}

Authors' Contribution: The present article has only one author.

Conflict of Interests: The author declares no conflict of interest.

Funding/Support: There was no funding or support.

\section{References}

1. Gupta S, Ajith C, Kanwar AJ, Kumar B. Surgical Pearl: Standardized suction syringe for epidermal grafting. J Am Acad Dermatol. 2005;52(2):348-50. doi: 10.1016/j.jaad.2004.06.041. [PubMed: 15692484].

2. Mukhtar M, Singh S, Shukla VK, Pandey SS. Surgical pearl: suction syringe for epidermal grafting.JAm Acad Dermatol.1997;37(4):638-9. doi: 10.1016/s0190-9622(97)70184-1. [PubMed: 9344206].

3. Mukhtar M. Disposable syringe cup for 3-way cannula-syringe suction. J Am Acad Dermatol. 2020. doi: 10.1016/j.jaad.2020.04.043. [PubMed: 32320765]. 

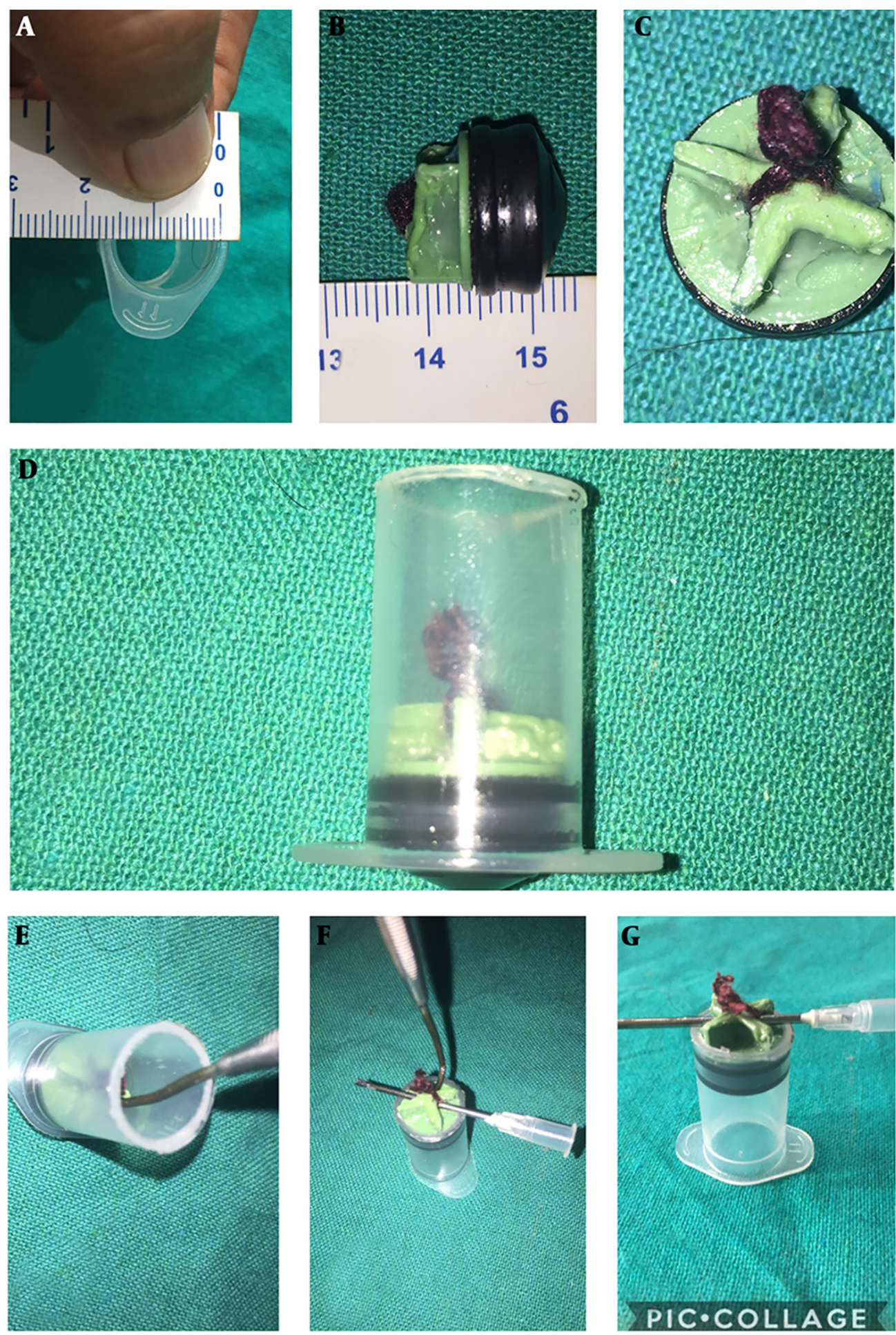

Figure 1. A-G, The modified suction syringe in its different stages (from measurement to application over the site) of modification. 

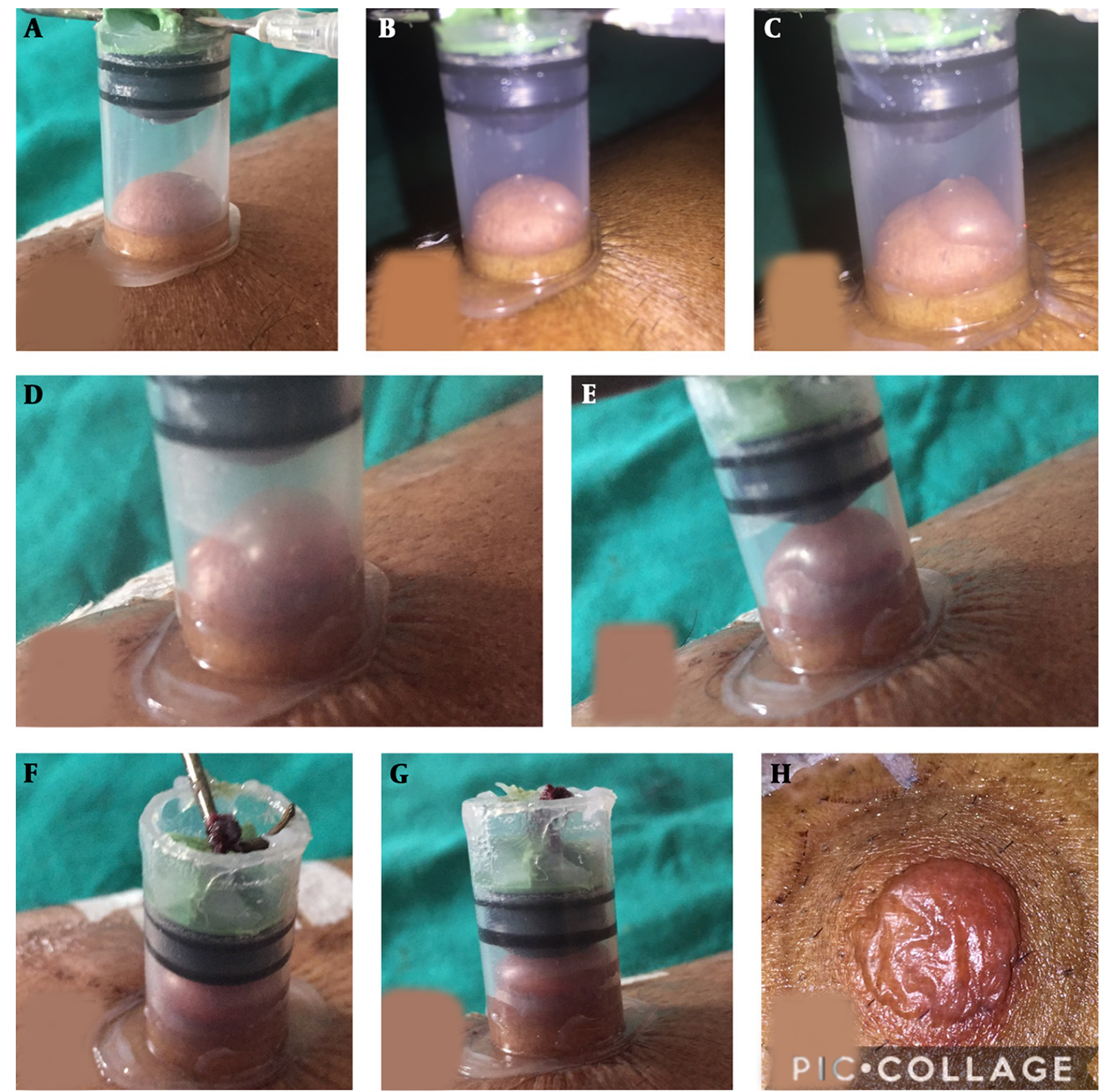

Figure 2. A-H, Suction syringe and its blister formation at its various stages. 